\title{
modelos vitivinícolas en mendoza (argentina): desarrollo y transformaciones en un periodo secular, $1870-2000^{\prime}$
}

\author{
Rodolfo A. Richard-Jorba \\ Instituto de Ciencias Humanas, Sociales y Ambientales (Conicet) \\ e Instituto de Geografía,Universidad Nacional de Cuyo-Argentina
}

\section{Reconstruyendo una imagen perdida}

La provincia de Mendoza,situada en el árido centro-oeste argentino, desarrolla lo fundamental de sus actividades económicas en dos grandes oasis de regadío que representan alrededor de un $3 \%$ de la superficie provincial. La utilización de las aguas de los ríos cordilleranos ha permitido poner en valor unas 450.000 ha en total, no todas cultivadas. En estos oasis se concentra el $96 \%$ de la población.

Acostumbrados los mendocinos y quienes visitan la Provincia a observar un paisaje de extensas y prolijas hileras de viñas o la umbrosa extensión de los parrales y, cada tanto, la clásica figura de añosas bodegas o modernas "fabricas" de vino, con enormes piletas cilindricas instaladas a cielo abierto, difícilmente pueden imaginar que hace poco más de cien años existía un paisaje diferente, casi una postal pampeana. Bien cuidadas sementeras de trigo, grandes alfalfares y multiplicidad de vacunos pastando semejarían lo que hoy se visualiza en Santa Fe o Buenos Aires, salvo por algunos detalles. El alambrado no estaba y su lugar lo ocupaba el alto muro de barro apisonado llamado tapia o la abigarrada trinchera de álamos; el horizonte de la gran llanura era reemplazado por el accidentado relieve pedemontano y precordillerano; y el verde inconmensurable de las húmedas pampas orientales no era el mismo, porque en Mendoza terminaba donde llegaban las acequias de riego que ponían

'Este artículo es una versión modificada y ampliada de! que fuera publicado en el libro Mendoza: una geografía en transformación, coordinado por Furlani de Civit y Gutiérrez de Manchón (1999). El Autor agradece las valiosas sugerencias de los evaluadores de esta Revista. 

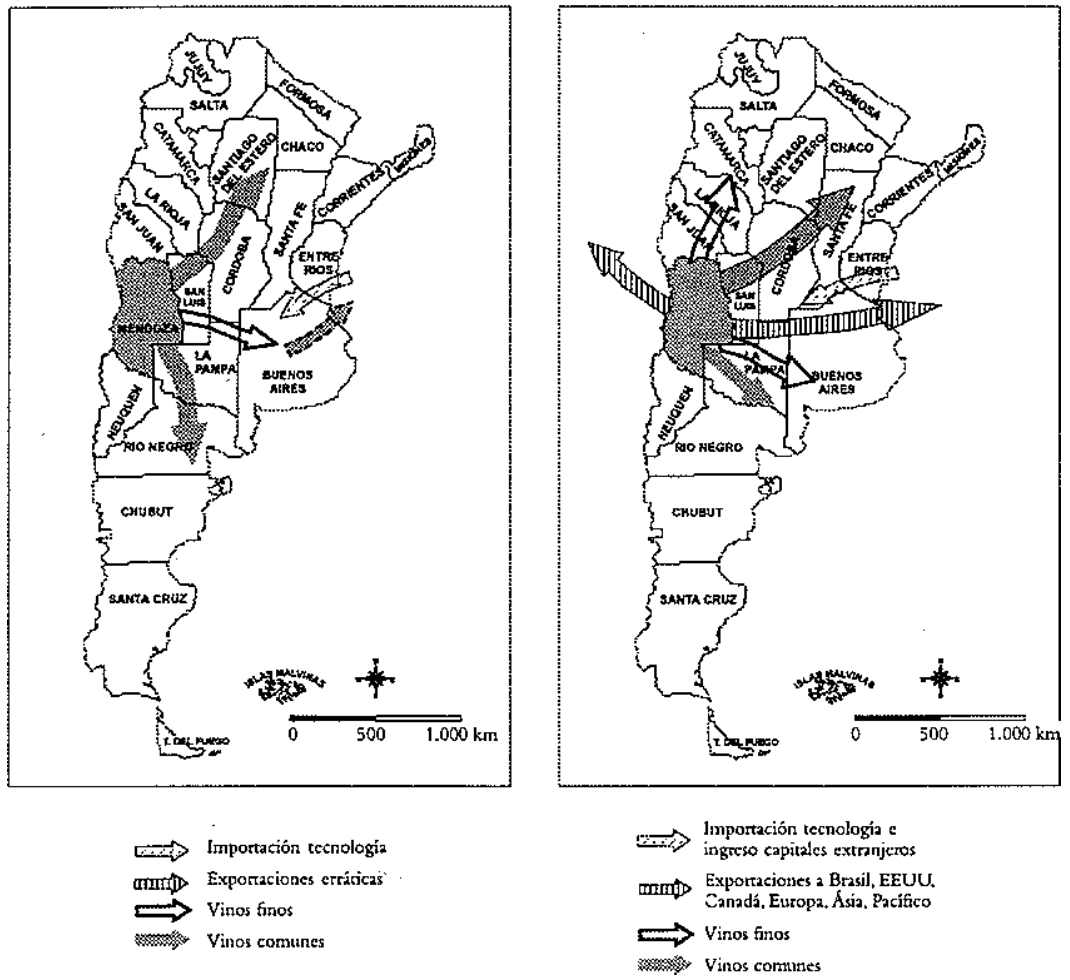

en evidencia la pequenez de un oasis en permanente tensión con el desierto circundante.

A lo largo del siglo XIX y hasta mediados de la década de 1880 , las producciones giraban en torno a la alfalfa, los cereales, el viñedo y los frutales, cultivos que constituyeron la agricultura del Oasis Norte. Construido y organizado por la ciudad de Mendoza, el diminuto espacio valorizado, era necesariamente cubierto por la sombra urbana, de modo que toda la actividad política, económica y social - en sus niveles decisorios - tenía su origen en la ciudad, es decir que existía un fuerte poder territorial.

En el secano, el espacio era ocupado por las "estancias", dedicadas a la cría de ganado de modo muy extensivo, en función de la escasez de 
agua y la baja receptividad de los campos. Los animales eran engordados en el oasis y posteriormente comercializados. Algunas grandes estancias crearon pequeños oasis en sus cascos utilizando agua de surgentes, arroyos, y construyendo tomas en los ríos, como sucedió en elValle de Uco o en el oasis Sur (San Rafael), luego de la creación de fortines militares para control de los indígenas.

La relativa autonomía provincial, desarrollada por la ausencia o por la debilidad de un poder central durante buena parte del siglo pasado y apoyada espacialmente en las condiciones físicas y en la inexistencia de comunicaciones y transportes rápidos, posibilitó una lenta configuración regional con Mendoza como núcleo principal. No obstante, cuando se estructuró definitivamente el Estado argentino moderno, Mendoza pasó a mediar, como otras ciudades, la influencia de la metrópoli nacional con su región.

El espacio mendocino ocupado durante la Colonia tuvo entre sus principales cultivos al viñedo, introducido desde Chile por los padres jesuitas y, desde el siglo XVII, los vinos locales llegaban al Litoral y a las misiones del noreste.

Durante el siglo XVIII, la vitivinicultura fue creciendo hasta convertirse en la actividad generadora de mayores riquezas, con su principal mercado situado en Buenos Aires. Hacia mediados de la década de 1780 entró en crisis y tuvo una gradual decadencia hasta casi desaparecer en la tercera década del siglo XIX por diversas causas, entre las que sobresalen el libre comercio borbónico (1778), las guerras de la Independencia, las civiles, la desprotección aduanera y la importación de vinos de calidad superior (Acevedo, 1981; Garavaglia, 1987). La ley de aduanas de 1835 , intento proteccionista, no logró una reactivación, de modo que a comienzos de los años 1850 la vitivinicultura casi había desaparecido y sólo atendía el mercado provincial y algunas áreas cercanas.

Para esos años, en el Oasis Norte, único espacio valorizado, se avanzó hacia un nuevo sistema productivo subordinado a una actividad mercantil. La alfalfa dominaba el paisaje; implantada en potreros destinados a engordar durante la estación invernal el ganado que se exportaba a Chile, llegó a representar en los años 1860 y 70 entre el 90 y el $95 \%$ de las superficies cultivadas. El resto correspondía a cereales - trigo en primer lugar - y, en una modesta posición, al viñedo, que comenzaba a recuperar significación mu gradualmente. Dificultades en el mercado chileno, la expansión de la agricultura y la ganadería pampeanas, los tendidos ferroviarios, entre otras causas, hicieron rescatar a la vid y el vino del olvido. 
El desarrollo que experimentó la vitivinicultura desde mediados de la década de 1870 , vertiginoso desde 1884 , montado con criterios capitalistas, condujo no sólo a la modificación del paisaje agrícola, caracterizado cada vez más por la presencia excluyente del viñedo y las bodegas, sino, esencialmente, a la formación de una economía regional que hoy da identidad nacional e internacional a Mendoza.

Los factores que intervinieron en aquella transformación, estaban vinculados con la inserción de la Argentina en el sistema económico global que construía el capitalismo industrial decimonónico hegemonizado por Gran Bretaña. Inserción periférica del País posibilitada por el progreso en la tecnología del transporte marítimo y por la necesidad de las economías industrializadas de abrir nuevos mercados para sus manufacturas. Como contrapartida, debía valorizarse el espacio pampeano, especializándolo como proveedor de materias primas agropecuarias, para lo cual se requirirían ingentes inversiones en infraestructura ferroviaria y un poblamiento acelerado con la incorporación de inmigrantes - mano de obra excedente de los países centrales - a cuyo cargo estaría el desarrollo agrícola argentino. Es decir, el desarrollo del capitalismo en el País se asimilaba al internacional y se gestaba en paralelo con la organización y expansión de un poder central que culminaría hacia 1880 con la consolidación del moderno Estado-nación argentino.

En consecuencia, durante las tres últimas décadas del siglo XIX, se gestó y consolidó un nuevo modelo de crecimiento basado en la vitivinicultura, cuyas características económicas y sociales básicas permanecieron casi inalteradas hasta un pasado reciente. El mejoramiento técnico posibilitó el desarrollo del cultivo del viñedo y abrió el camino para la conformación de un sistema agroindustrial motorizado por la gran bodega mecanizada, orientado al mercado interno y perfectamente integrado en un nuevo espacio funcional que vinculó a Mendoza con el resto del territorio nacional y, en una escala mayor, con el espacio económico global. En la actualidad, la denominada globalización económica está determinando un nuevo ciclo modernizador, que incluye la transnacionalización del capital y una sostenida inserción de los vinos mendocinos en el mercado internacional.

Este artículo traza un panorama de los cambios operados en la vitivinicultura mendocina en un período de más de cien años, señalándose las innovaciones verificadas en cuestiones institucionales, empresariales, técnicas y laborales, muchas de las cuales han constituido respuestas adaptativas a circunstancias críticas no controlables desde la Provincia. 


\section{La economía y el espacio entre 1850 y 1880}

La decadencia de la vitivinicultura de raíz colonial se hizo ostensible en la Provincia a comienzos de la década de 1830 , momento en que comenzó una expansión de los alfalfares y los cultivos cerealeros, acompañada por el crecimiento de la actividad molinera (RichardJorba, 1998). La reanudación de las ventas de ganado a Chile, que aseguraba buenas ganancias a los comerciantes y transportistas mendocinos, puede haber influido también en el estancamiento y retroceso de la vitivinicultura y, hacia los años 1850 , como ya se expresó, el vino producido sólo atendía la demanda local y la de San Luis. En esos años, el ingreso de Chile a los mercados de trigo y harina del Pacífico y la ocupación de su suelo con cultivos cerealeros, determinó una explosiva demanda de ganados argentinos, atendida principalmente desde Mendoza y San Juan.

La economía mendocina se estructuró entonces en torno a la exportación de ganado a Chile, para lo cual organizó su espacio productivo con una agricultura subordinada a tal comercio. El ganado, adquirido en Córdoba, Santa Fe, San Luis y aún Buenos Aires, era engordado en los alfalfares del oasis y, cuando los pasos cordilleranos quedaban expeditos, se lo exportaba al mercado trasandino. Aquellas compras de ganado generaban fuertes desequilibrios financieros con el este del País que obligaban a Mendoza a remitir frutas secas, harinas, alfajores, tabletas, jabón, vinos, etc., para compensar el déficit, aunque sólo fuera parcialmente. Por el contrario, la exportación de los animales a Chile dejaba importantes ganancias que permitían la acumulación de capitales en la región.

A través del comercio y los servicios de transporte - mayoritariamente en manos de propietarios locales, que además controlaban la tierra, las finanzas y el poder político - Mendoza se había convertido en eje articulador de un espacio funcional integrado por una zona productora de ganado y una consumidora.

Internamente, el espacio valorizado estaba organizado desde la ciudad capital. Pocos propietarios y una escasa división de las explotaciones caracterizaban al oasis, en correspondencia con los cultivos predominantes, pastos y cereales, que requerían importantes extensiones para ser rentables. La mayor división se registraba en las tierras irrigadas en torno a la ciudad, zona de poblamiento original. Fuera del oasis, en montaña o llanura, campos de cría de ganado y de extracción de leña y madera completaban el esquema de utilización del suelo. 
Los cereales eran cultivos itinerantes - se sembraban para incorporar nuevas tierras o renovar, cada 10 o 12 años los alfalfares - y la forrajera el ocupante permanente de las explotaciones del oasis. La viña se incorporaba a estos prados asociada con alfalfa, razón por la cual era cultivada muy extensivamente, con escasa densidad de cepas por unidad de superficie, pues la forrajera era el objetivo central de la actividad agraria. Cabe agregar que la diversificación agrícola aparecía nítidamente en las áreas de tierras subdivididas, ubicadas en la capital y su entorno. El lugar secundario de la vitivinicultura queda de manifiesto, además, en la exigua cantidad de bodegas que elaboraban vino y aguardiente, registradas por el Censo de 1864: sólo 56 establecimientos. Eran apenas artesanales, con lagares de cuerovacuno, uva pisada con los pies y procesos rudimentarios de fermentación y conservación. Sin edificios adecuados, la mayoría de las bodegas eran simples ranchos o ramadas (PachardJorba y Pérez Romagnoli, 1992).

Elviñedo tradicional creció muy lentamente durante los años setenta, manejado con técnicas primitivas. Se cultivaba con el sistema español denominado "de cabeza". Cada planta estaba conducida por un tutor o rodrigón. A comienzos de la década de 1870,1 as cepas no superaban el millar por hectárea y hacia finales de los ochenta, llegaban a 1.600. Este sistema no requería labores culturales - salvo alguna poda - ni técnicas destinadas a mejorar la producción, en cantidad y calidad, porque ello entorpecería el desenvolvimiento de la alfalfa.

La vid existía entonces como un cultivo accesorio, con bajos rendimientos y calidad ausente, pues los cepajes criollos, de escasa aptitud enológica, sólo daban vinos comunes - tinto, blanco y, predominantemente, carlon (rosado o criollo). No obstante, hubo excepciones. Dentro del marco de atraso tecnológico, algunos productores obtenían uvas y vinos de calidad, premiados en exposiciones industriales en el País, como Córdoba (1871) y Buenos Aires (1877), y en el extranjero(París, 1878), pero su número era insignificante. Se trataba en realidad de un círculo muy restringido de productores innovadores, tanto argentinos (familias Civit, González, Estrella...), como inmigrantes europeos de la etapa temprana, anterior a los años setenta (el italiano Pedro Brandi y los franceses Eugenio Guerin e Hilaire Lasmartres).

Alrededor de 1875 , los rendimientos de los viñedos oscilaban como

El rancho es una construcción de barro apisonado o de adobe (ladrillo crudo), con techo de caña y barro. La ramada es un conjunto de postes de madera, sin paredes, $y$ techos de caña y barro. 
máximo entre 94 y 125 quintales (de $46 \mathrm{~kg}$ ) de uva por ha, que resultaban entre 30 y $40 \mathrm{Hl}$ de mosto. El excedente de vinos y aguardientes exportables a otras provincias era calculado en 20 mil arrobas $(6.600$ H1), aunque no había seguridad de que pudieran ser vendidos (El Constitucional, 16-1-1877). Esos saldos representaban un ingreso posible de 120 mil pesos bolivianos (aún no existía la moneda nacional), menos de un $10 \%$ de las ventas externas de la Provincia, indicativo de la todavía escasa significación de la vitivinicultura.

\section{La primera modernización}

El desarrollo capitalista argentino, como se ha expresado, llegaba impulsado por la inserción del País en la economía internacional estructurada con hegemonía británica. La denominada división internacional del trabajo era un modelo de desarrollo - surgido de las triunfantes ideas librecambistas a mediados del siglo XIX - que, simplificadamente, consistía en el intercambio de manufacturas industriales por materias primas. La revolución tecnológica aplicada a los medios de transporte permitió la rápida integración de los mercados internos en Europa con los tendidos ferroviarios. Los cambios en el diseño y capacidad de carga de los barcos desde los años 1850, redujeron los tiempos y costos de transporte, valorizando espacios lejanos, que fueron incorporados a la producción exportable (Lilley, 1983). Las pampas argentinas lo hicieron desde la década de 1840 con la especialización en ganadería lanar (Sábato, 1989). Sin embargo, la expansión capitalista tomaría auge luego de la sanción de la Constitución Nacional (1853) y, sobre todo, con posterioridad a la batalla de Pavón (1861), cuando la triunfante Buenos Aires impondría el liberalismo en el País.

Las actividades económicas de espacios geográficos de diversas zonas del mundo se fueron integrando como elementos interdependientes en un sistema global. Este sistema reunió diversas características, entre las que se destacaba la especialización económica de los países integrados y la aceleración y elevación de sus tasas de crecimiento económico y demográfico, acompañado por un aumento en los salarios reales. Otro aspecto esencial era la formación y rápida difusión de los conocimientos técnicos fácilmente transferibles comercialmente (Furtado, 1969). La transferencia de conocimientos transformaba sectores productivos enteros con una rapidez desconocida hasta entonces. Con su industria ferroviaria y naval, Inglaterra revolucionó los medios de transporte en todo el mundo y promovió - de acuerdo con sus intereses - la integración 
de un gran mercado internacional. Asimismo, el desarrollo industrial británico generó excedentes de capital financiero que fueron exportados, contribuyendo decisivamente a la constitución de este sistema económico mundial.

\section{Especialización espacial y productiva: El viñedo como nuevo eje económico}

La modernización del viñedo mendocino comenzó a mediados de la década de 1870 como consecuencia de decisiones políticas de la élite local y del accionar del gobierno nacional. Era una respuesta a diversos factores que crearon las condiciones para el cambio del modelo de acumulación vigente en la Provincia en esos años, aunque vinculados todos con la consolidación de la orientación atlántica de la economía nacional y su inserción internacional. El avance hacia el oeste de la nueva agricultura pampeana y el desarrollo de una moderna industria harinera, junto con la expansión de las líneas ferroviarias, determinaron la pérdida de competítividad de las principales actividades mendocinas: traslado de ganado en pie, su engorde en el oasis y producción de cereales y harinas, sebos y cueros, a lo que se sumaba una gradual retracción de la demanda ganadera en el mercado chileno, la depreciación e inconvertibilidad de la moneda trasandina, etc. Por otra parte, el masivo ingreso al País de inmigrantes - en su mayoría originarios de la cuenca del Mediterráneo, zona de fuerte consumo de vino - ampliaba aceleradamente el mercado de productos vínicos, atendido con producción importada por insuficiencia de la oferta nacional. En el plano político, el desarrollo gradual del Estado-nación requería, para su consolidación, la atenuación de conflictos con las provincias y la formación de dirigencias nacionales mediante la incorporación o la cooptación de las élites regionales, es decir, el control de las denominadas situaciones provinciales. Para ello, era esencial lograr una adecuada evolución económica en ciertas regiones, por caso, Mendoza en el centro-oeste y Tucumán en el noroeste. El viñedo fue elegido entonces como una alternativa viable y rápida para que la provincia cuyana superara situaciones de crisis y reiniciara el crecimiento.

Una clara actitud modernizante se instaló gradualmente en miembros de la élite y hubo diversas iniciativas individuales tendientes a mejorar los viñedos y la elaboración de vinos mediante la difusión de información técnica. En tal sentido es destacable la edición del Manual del Viñatero en Mendoza (1870), de Eusebio Blanco, que extractó y anotó, con ejemplos 
de Mendoza y consejos para vinicultores, el Tratado deVinificación del enólogo francés H. Machard. Pero el verdadero generador del cambio fue el núcleo de la élite, liderado por Francisco Civit y su hijo Emilio, acompañados por otras personalidades, como el propio Blanco, los Villanueva, los Benegas, los Zapata, etc. Sus acciones, emprendidas desde el poder político, impusieron el modelo agroindustrial vitivinícola en la Provincia. De modo similar, aunque no idéntico, la provincia de San Juan se especializó en vitivinicultura.

\section{La intervención estatal}

El Estado se involucró mediante medidas provinciales, contando con importante apoyo nacional, y consistieron en exenciones impositivas, extensión del crédito, formación de recursos humanos y fomento de la inmigración. El mayor y fundamental aporte del gobierno federal fue la construcción del Ferrocarril Andino, habilitado en 1885 , que conectó Villa Mercedes (San Luis) con Mendoza y San Juan, vinculando el centro-oeste con los mercados de Buenos Aires, el Litoral y el norte del País.

A partir de 1874 se pusieron en vigencia disposiciones legislativas de promoción de los cultivos de vid, olivos y nogales. En aquel año, una ley instituyó premios en dinero para quienes iniciaran nuevas explotaciones, aunque no tuvo efecto alguno, probablemente porque fallaba la transmisión de la información referida a los incentivos fijados, así como la percepción de los actores sobre la profunda reorganización que transformaba la economía argentina. En 1875, la ley impositiva provincial fijó tasas diferenciales en el denominado impuesto territorial (contribución directa) para los cultivos, con índices menores para las viñas. Una ley de 1881 , aplicada efectivamente desde 1884 , eximió de impuestos provinciales a las nuevas plantaciones de viñas, olivos y nogales, hasta 1891 inclusive. Leyes posteriores $(1889,1895,1902)$ fijaron períodos de cinco años sin impuesto territorial al viñedo, de modo que el productor comenzaba a pagar cuando su explotación producía en plenitud. El Estado subsidiaba así, parte de la inversión privada, aunque se aseguraba una muy buena fuente de ingresos a futuro. En efecto, para 1907, más del $60 \%$ de los ingresos tributarios de la Provincia eran aportados por la vitivinicultura.

Los resultados fueron positivos: entre 1884 y 1900 se iniciaron 2.900 explotaciones de viñedos modernos con una superficie de 17.830 ha, 1o que representó un $640 \%$ de aumento respecto del padrón base de los viñedos tradicionales existentes en 1883. El cambio espacial y económico 
fue destacadísimo. En primer lugar, transformó el paisaje, porque estas leyes obligaban a la implantación exclusiva de viñedos, con lo cual se eliminaba la alfalfa, otrora cultivo principal y se imponía,implícitamente, una alta densidad de cepas por hectárea para tornar rentables las nuevas explotaciones que, en su mayoría eran menores de 5 ha. De manera tal que, en muy pocos años, los nuevos viñedos se intensificaron, alcanzando densidades promedio de 3.100 cepas por ha en 1888 y 3.700 en $1895 / 96$.

Gracias a los sistemas técnicos modernos, el aumento de los rendimientos fue extraordinario. Los 120 quintales españoles (de $46 \mathrm{~kg}$ ) de uva por ha que aproximadamente se obtenían en los años 1870 , se convirtieron en 250 a fines de la década siguiente y el mosto obtenido duplicaba holgadamente los registros anteriores. La creciente ocupación del oasis con viñedos y los grandes rindes aumentaron la oferta de uva y determinaron el desarrollo de una auténtica industria del vino, con bodegas tecnificadas, iniciándose un notable proceso de sustitución de importaciones.

Esta política fiscal fue, de todas, la más exitosa y de impacto inmediato y duradero a la vez, como que el modelo sigue parcialmente vigente hoy, aunque en proceso rápido de reconversión.

Respecto de políticas crediticias, el gobierno local estableció en la ley de creación del Banco de la Provincia (1888) "hacer préstamos sobre hipoteca al soló efecto de fomentar la plantación de la vid" (Art. 10). Los bancos nacionales también operaron en este sentido.

La formación de recursos humanos tuvo resultados modestos. E1 Gobierno Nacional creó el Departamento Agronómico en el Colegio Nacional (1872-1880), pero la preparación de los alumnos, numéricamente escasos, fue muy deficiente. La Escuela Nacional de Agricultura, que le sucedió,fue administrada por el gobierno provincial desde 1887 , año en el que comenzó la inclusion de estudios sobre vitivinicultura. La educación técnica y la capacitación de personal marchaban desfasadas en el tiempo respecto del proceso modernizador. El gobierno mendocino, durante la gobernación de Tiburcio Benegas (1887), envió tres becarios a estudiar en Europa. Dos de ellos, agronomía y enología; el restante, veterinaria, para atender la actividad ganadera, que conservaba todavía un destacado lugar. A su regreso, si bien tuvieron una buena actuación profesional y docente desde la década de 1890 , su escaso número limitó, de hecho, la difusión de los conocimientos adquiridos. Sólo a partir de 1896, con la creación de la Escuela Nacional de Vitivinicultura (sobre la base de la anterior) hubo una verdadera oferta edu- 
cativa apta para dar respuesta a los problemas agrícolas e industriales de la actividad, pero fue poco demandada porque las bases del modelo estaban firmemente asentadas y en expansión, con una tendencia claramente orientada hacia la gran producción de masa. Viñateros y bodegueros trabajaban mayoritarlamente en forma empírica con un solo objetivo: producir mucho con la ganancia más alta posible.

Con relación a la inmigración, hubo acciones gubernamentales nacionales y provinciales - destinadas a promover el ingreso irrestricto de profesionales y de viticultores. Por ejemplo, un inmigrante francés, el Ing.Agr.Jean Recapet, fue contratado en 1876 por la Provincia para que difundiera entre los productores las técnicas necesarias para un cultivo científico de la vid.

La Provincia procuró además atraer una inmigración selectiva en la década de 1880; hombres que fueran "prácticos en toda labor agrícola, con especialidad en el cultivo de la vid y la elaboración de vino" (Registro Oficial, 1884:84), o encomendando la contratación en Europa de 400 personas "destinados al cultivo de la vid en esta Provincia..." (Registro Oficial, 1884:180). Lo cierto es que una mínima proporción de los que arribaron eran agricultores y sólo una escasa cantidad de éstos se reconocían como viticultores. La mayoría eran trabajadores que dejaron sus países en busca de mejores oportunidades económicas y dispuestos a encarar cualquier tarea. Como la escasez de mano de obra en Mendoza era crónica, encontraron ocupación sin dificultades, al menos hasta la primera década de este siglo. Eran años en que el factor trabajo se movilizaba internacionalmente sin dificultades, generando las más grandes migraciones de la historia. Argentina en general, y Mendoza en particular, se beneficiaban de este proceso motivado, entre otros factores, por la modernización agrícola y por el desarrollo industrial europeo que expulsaban mano de obra, es decir, lo que hoy conocemos como tecnodesempleo.

En síntesis, la fuerte intervención del Estado en función promotora, constituyó una notable innovación institucional y resultó en una efectiva promoción y modernización de la viticultura, que sustituyó a otros cultivos y avanzó hacia el predominio económico y espacial, aunque se trató de una expansión esencialmente cuantitativa, masiva, sin selección de cepajes finos para obtener vinos de alta calidad.

\section{La difusión y aplicación de las técnicas de explotación vitícola}

En los comienzos de la década de 1870 se difundió paulatinamente información técnica a instancias del Gobierno Nacional, interesado en 
valorizar rápidamente el territorio, promoviendo la agricultura en gran escala, en especial en la región pampeana. Cumplieron un papel destacado en tal sentido las delegaciones provinciales del Departamento Nacional de Agricultura y las escuelas y estaciones experimentales creadas posteriormente. En Mendoza se registró también el ingreso de bibliografía técnica extranjera y alguna de producción nacional, como el mencionado Manual del Viñatero en Mendoza, aunque cabe suponer, con bastante seguridad, que su difusión fue limitada y lenta, ya que los métodos tradicionales de explotación vitícola dominaron en el sector hasta fines de la década del ochenta. Algunos de los autores extranjeros conocidos en Mendoza, fueron el italiano Giuseppe Frojo (1877) y los franceses L.Oudart (1873) — citado por Pavlovsky en 1885 - Jules Guyot (1881) - tal vez el que tuvo mayor influencia técnica en Mendoza Lafitte, Lamotte, Mas y Pulliat (catalanes?), etc.

Eusebio Blanco promovió, en su Manual, un cultivo de cepajes de calidad, implantados de acuerdo con los diferentes tipos de suelos, clasificándolos por cuarteles y perfeccionando las variedades a fin de "prepararnos poco a poco para salir de la rutina de hacer vinos comunes, fabricados según la práctica transmitida por nuestros respetables abuelos" (Blanco, 1870:15) y desplazar del mercado argentino a los vinos importados, o al menos competir con éxito contra ellos.

Las publicaciones y el accionar de la delegación local del Departamento Nacional de Agricultura motivaron a la prensa en Mendoza y contribuyeron a establecer una cadena informativa que creció en cantidad y calidad. A ello se sumaba, sin duda, el efecto-demostración que cumplieron algunas explotaciones vitícolas, "modernas" para esos años fundacionales. Tal vez las más destacadas eran las de Salvador Civit, hermano de Francisco (gobernador 1873-1876) y líder del grupo más modernizante de la élite. Un informe de la Inspección Nacional de Agricultura (18-1-1876), sugería a los productores que abandonaran el cultivo de la alfalfa y lo sustituyeran porviñedos y frutales porque el negocio ganadero estaba en declinación. Reproducía también consejos técnicos de S.Civit, hombre que gozó de reconocimiento nacional por sus trabajos como viticultor y enólogo y su manejo de la ampelografía, pese a ser autodidacta. Civit aconsejaba implantar unas 2.500 cepas por cuadra cuadrada (1.600 plantas por ha) (Informe reproducido en El Constitucional, 12-7-1877).

E1 sistema de conducción tradicional, además de impactar en el ambiente y acelerar la destrucción del monte nativo, aumentaba el costo de implantación, pues los tutores de algarrobo, retamo o atamisque 
debían traerse de 30 o 40 leguas. El elevado precio de la madera para postes posiblemente fue uno de los factores que indujeron la introducción y difusión del alambrado en Mendoza y el cambio en los sistemas de conducción; sobre todo a partir de la mayor densidad en los cultivos consecuencia de las políticas de promoción vitícola de la década del ochenta. El ferrocarril cumplió en este aspecto un papel definitorio por su capacidad de transportar grandes volúmenes. Otro de estos factores puede ser atribuido al aporte cultural de los inmigrantes franceses arribados a la Provincia desde 1875. Ellos introdujeron técnicas diversas, tales como la conducción en espaldero, la poda según el sistema Guyot "doble", posteriormente innovado localmente y transformado en "triple" o "mendocino", etc. (Richard-Jorba, 1994c).

En un informe elaborado por el director de la Escuela Nacional de Agricultura, Ing. Pavlovsky, para el Ministro del Interior (1884), se destacaba que la viticultura estaba aún en estado primitivo, aunque "cada año adquieren, sin embargo, un desarrollo más y más vigoroso" los nuevos viñedos, habiendo iniciado algunos propietarios la "plantación en grande escala", como Tiburcio Benegas,el gobernador Rufino Ortega, Salvador Civit y otros (Pavlovsky, 1884:16).

En fin, hacia 1887, Emilio Civit sugería desde Francia la adopción de los métodos de Burdeos (2.400 cepas/ha y conducción con 2 alambres) (Civit, 1887); y Lemos, un año más tarde, prescribía 3.400 cepas para las variedades francesas y 2 mil para las criollas ${ }^{3}$, ambas con conducción en espaldero. Los resultados superaron esas cifras: entre 1888 y 1896, la densidad promedio en los viñedos de la Provincia, como fuera expresado, pasó de 3.140 cepas a 3.704 (RichardJorba, 1994c).

Los viñedos modernos implantados en las décadas de 1880 y 1890 se caracterizaron por ser cultivos intensivos, densos, con técnicas de plantación, conducción y formación de las cepas orientadas a lograr una gran producción, en perjuicio de la calidad. La magnitud del trabajo humano queda reflejada en las cifras: en sólo trece años (1888-1900), se implantaron casi 50 millones de cepas, técnicamente tratadas para producir la uva que requería la naciente agroindustria vinícola para satisfacer la creciente demanda de vinos en el mercado nacional.

Desde un comienzo, el nuevo modelo de desarrollo sufrió un desvío

"La denominación "francesa" se aplicaba genéricamente a todas las variedades de vitis vinífera traídas del exterior (francesas, italianas, etc.), por oposición a los cepajes locales, adaptados al medio desde la época colonial, llamados "criollos" y caracterizados por su alto rendimiento y baja calidad. 
respecto del ideado por la élite que lo impulsó. Se soslayaron las ideas de llegar a una producción de calidad capaz de competir con los vinos finos de ultramar propuestas por Eusebio Blanco (1870) y por Emilio Civit (1887) y la mayoría de los esfuerzos se orientaron a la masividad.

La exclusión de otros cultivos asociados determinó en pocos años la dominancia de una agricultura especulativa, que no sólo modificó el uso del suelo y se expandió por los oasis, sino que hegemonizó la economía provincial y conformó,junto con San Juan, una de las llamadas economías regionales, de la Argentina.

El Cuadro N. ${ }^{\circ} 1$ muestra claramente la evolución de la superficie implantada con viñedos en las dos últimas décadas del siglo pasado. A las 2.788 ha de viñas tradicionales en producción en 1883 , se agregan las plantaciones modernas surgidas al amparo de la promoción estatal. La división por quinquenios permite apreciar la influencia de la llegada del ferrocarril (1885), que junto a la inmigración, provocaría una verdadera "explosión" en las superficies ocupadas.

Cuadro N. ${ }^{\circ}$ 1: Provincia de Mendoza. Evolución de la viticultura .Viñedos tradicionales existentes en 1883 y viñedos modernos implantados entre 1881 y 1900, por quinquenio, en ha.

\begin{tabular}{lccccc}
\hline $\begin{array}{l}\text { Padrón base } \\
1883 \text { (viñedo } \\
\text { tradicional) }\end{array}$ & \multicolumn{6}{c}{ Viñedos modernos implantados con promoción fiscal } & $\begin{array}{c}\text { Total } \\
\text { General }\end{array}$ \\
\hline & $1881-1885$ & $1886-1890$ & $1891-1895$ & $1896-1900$ & \\
\hline 2.788 & 174 & 4.462 & 7.248 & 5.946 & 20.618 \\
\hline
\end{tabular}

Fuente: elaboración propia con datos tomados del Primer Padrón de Viñas existentes. Mendoza. 1883 (Archivo Histórico de Mendoza) y el procesamiento de 2.900 decretos de exención impositiva dictados entre 1884 y 1900 (Gobierno de Mendoza, Registro Oficial, Ministerio de Hacienda, años 1884 a 1900 inclusive).

La intensificación de los cultivos vitícolas, su mantenimiento y particularmente la vendimia, aumentaron la demanda de mano de obra, en contraposición a lo que sucedía con la agricultura de forrajeras y la ganadería. Aunque no se dispone de datos fehacientes sobre el empleo generado por la viticultura, es interesante destacar el aumento que tuvo la población rural en Mendoza entre los Censos de 1869 y 1895 , que alcanzó un 54\%. En el primero dominaba la economía ganadera y la actividad vitícola era insignificante; en el segundo, el nuevo modelo estaba en plena expansión. En 1895, el Segundo Censo Nacionalindicaba 10.460 personas empleadas en los establecimientos bodegueros $(8.434$ en vendimia y 2.026 permanentes), es decir en el sector industrial. 
Otras estimaciones posteriores incluyen siempre las etapas agrícola e industrial, sin desagregaciones. Bialet Massé calculaba 15.000 personas en el sector en 1904 (Bialet Massé, 1986:879-880); y en 1910, 21.760 personas trabajaban en la industria, entre personal permanente y temporario (Richard-Jorbay Pérez Romagnoli, 1994:44 ), Io que significaba un $10,5 \%$ de la población total de la Provincia registrada en el Censo Provincial de 1909 (206.393 habitantes), empleada directamente en la actividad de transformación.

\section{La bodega. Factor de industrialización}

La rápida difusión de los viñedos modernos y el sustancial aumento de la producción multiplicó la oferta de uva. La abundancia de materia prima y la creciente demanda de vinos en el mercado nacional en formación sólo podía ser articulada por verdaderos establecimientos industriales, es decir, que los procesos de elaboración debían cumplirse en edificios especialmente preparados y dotados de equipos capaces de acelerar las diversas operaciones hasta llegar al vino. Obviamente, la bodega artesanal, de tradición tecnológica colonial, no estaba en condiciones de acoplarse a las transformaciones en marcha. Al finalizar la década del ochenta, del total de bodegas inscriptas,"dos son únicamente de importancia, por la cantidad de vino que fabrican. La primera es la de D. Honorio Barraquero y la otra de Serú y Cía."(Lemos, 1888:129). Por supuesto, había algunas más, consolidadas o en vías de expansión (Benegas, Brandi, Civit, Dellaballe, Givaudant, Lasmartres,Tomba...).

Emilio Civit en carta a su suegro, el gobernador Tiburcio Benegas, confirmaba el atraso en que se desenvolvía la vinicultura y prevenía que "ya es tiempo de salir de semejante situación dado el desarrollo que toma la industria...y el porvenir que le está reservado...Todo es cuestión de construir buenas bodegas y de poner al frente de ellas hombres capaces de dirigirlas y no sofisticadores y falsificadores desvergonzados y groseros"(Civit, 1887: 25-27).

Las nacientesfábricas de vino, como las denominaba el Censo de 1895 , adoptaron en su mayoría formas propias de algunas regiones europeas con larga tradición vitivinícola, aunque sin imitar fielmente el diseño, el tamaño y los materiales empleados en la construcción.

Entre los avances registrados en la década del noventa, cabe señalar la reunión de todas las operaciones de elaboración en el edificio central. La introducción y la rápida difusión de máquinas que reemplazaban fuerza humana - la única empleada en la antigua bodega - con energía 
a vapor y eléctrica, supuso una nueva división técnica del espacio y del trabajo en el interior de los establecimientos. Al mejorarse gradualmente la vasija - de fermentación y de conservación — se comenzó a abandonar el álamo como materia prima por otras maderas. Las cubas más aptas - y costosas - eran las de roble (europeo y norteamericano), introducidas por los empresarios industriales más dinámicos, preocupados por obtener caldos de cierta calidad.

El alto valor de las vasijas importadas llevó a muchos industriales a construir piletas de fermentación en manipostería revestida con cemento, siguiendo el ejemplo de países europeos, pero también aconsejados por las experiencias llevadas a cabo en la Escuela Nacional deVitivinicultura.

Un enólogo italiano, de reconocido prestigio en la época y dilatada actuación en Mendoza, sintetizaba agudamente el estado de la industria mendocina;

"En aquel vasto campo de actividad comercial se advierten ios métodos más rudimentarios, como los más progresistas...Existen, en fin, en la Provincia, verdaderos establecimientos vinícolas y verdaderos abortos de bodegas..." (Galanti.1900:93).

Como se aprecia, este experto coincidía, 13 años después, con la evaluación hecha por Emilio Civit. Inclusive, en la primera década del siglo XX no se registraban avances sustanciales, salvo excepciones, como reconocía la Comisión de Investigación Vinícola en 1903.

Persistía como un serio problema en la época el desfasaje existente entre la creciente oferta de uvas y la escasa capacidad de elaboración de las bodegas, lo que motivaba la prolongación de las vendimias, hecho que incidía directamente en la deficiente calidad de los vinos producidos. En la década del noventa, reconociendo la incapacidad del sector industrial para procesar toda la producción, el gobierno de Francisco Moyano autorizó la venta de uvas fuera de la Provincia, lo que era aprovechado por elaboradores y comerciantes inescrupulosos del Litoral y Buenos Aires, para realizar fraudes vínicos que desprestigiaban la vitivinicultura local y generaban efectos económicos negativos que impactaban no sólo en los empresarios sino también en elfisco. En este último caso, menores ventas de vino reducían la percepción de impuestos; en tanto que los fraudes significaban lisa y llanamente evasión de gravámenes.Todo se combinaba, además, para perjuicio de la sociedad: destrucción de empleos y ataque a la salud de los consumidores.

El modelo, contrariamente a lo que sucedía en la paradigmática Fran- 
cia, disociaba la producción y sus actores, dividiéndolos, en general, entre viñateros "independientes" y bodegueros ${ }^{4}$.

Equipamiento industrial y desarrollo tecnológico

Desde mediados de la década del ochenta comenzó a ingresar a la Provincia equipo parabodegas tecnológicamente avanzado, desde filtros y bombas manuales a prensas y alambiques, que se fueron incorporando al espacio productivo con un retraso de al menos 15 años en relación con las regiones vitivinícolas de Francia. En la década de 1890 el cambio se aceleró, en cantidad y variedad de equipos introducidos. Después de 1895 numerosas bodegas se tecnificaron para poder procesar la mayor cantidad de uva posible y terminar los vinos cuanto antes para expedirlos al mercado. Se trataba en general de un proceso de construcción de nuevas bodegas, con tamaño y diseño que buscaba adaptarse a las nuevas condiciones productivas, acompañado de equipos cada vez más complejos (moledoras con separador de escobajo, prensas hidráulicas - móviles y continuas —, refrigerantes para controlar la fermentación, pasteurizadores para prevenir el deterioro de los vinos...). En fin, en 1897 se ensayaba en la bodega Trapiche con una bomba rotativa para generar electricidad "... de fuerza de un solo caballo. Los resultados obtenidos son excelentes y quedó constatado que una bomba de este sistema hace el trabajo de dos, movidas a mano, ahorrándose el trabajo de ocho hombres por día".

'Este modelo vitivinícola generó diversos actores integrados en relaciones asimétricas. El viñatero era un propietario o arrendatario que explotaba, en general, fincas menores a 5 ha y vendía la uva al elaborador de vinos. El productor agroindustrial integraba la producción de uva y elaboraba vino en establecimientos de tamaño variable, aunque con predominio de los pequeños.Vendían su producción en el mercado local, en ocasiones a otras provincias y también a grandes bodegas. El industrial bodeguero poseía o arrendaba bodegas y no producía la materia prima. Fue una categoría de transición hacia fórmulas empresariales integradas.El bodeguero integrado era, a fines del XIX, una excepción. Su desarrollo de manifestaría desde la década del 1900 como fruto de la maduración del sector. Cubría todas las etapas, desde la producción de uva hasta la comercialización del vino. Constituyeron un reducido grupo de grandes bodegueros con capacidad para controlar la industria e intervenir en la fijación de precios. Alcanzaron, además, notable influencia y presencia en la política provincial. Finalmente, los comerciantes extrarregionales distribuían en otras provincias los vinos locales o los compraban a granel para fraccionarlos con marcas propias.Perdieron importancia en las dos primeras décadas del siglo XX (Richard-Jorba, 1998). 
"E1 fuído eléctrico es un obrero esclavo pues ni se rinde, ni consume ni subleva; honrando y enriqueciendo al amo... en vez de deprimirle con su servidumbre, o de perjudicarle con sus huelgas y torpezas"(Kexe1, 1897:1, resaltado nuestro).

Esta cita pone de manifiesto no sólo la concepción que algunos sectores sociales tenían del trabajador, sino también el afán de innovar que caracterizaba la época. Pero además es significativa porque deja en claro el impacto social de las nuevas tecnologías, traducido en un aumento de la productividad del trabajo y en la sustitución creciente de fuerza laboral.Y esto generaba una transformación en la estructura social, tanto por la pérdida de puestos de trabajo - el tecnodesempleo y sus conocidos efectos afectaban entonces a Mendoza - como por la permanente capacitación de quienes seguían empleados, todo lo cual motivaba una redistribución de la riqueza producida, con crecientes y mayores beneficios para el empresario que invertía en el mejoramiento técnico (Richard-Jorba y Pérez Romagnoli, 1994).

A fines de los 1890 numerosos indicios sugieren que algunos talleres mendocinos comenzaron a copiar y construir equipos parabodegas, de baja complejidad, como alambiques para destilar alcohol, pasterizadores, prensas y bombas manuales, etc. Una notable excepción fue el taller del ingeniero italiano Carlos Berri, cuyo establecimiento - fundado en 1888 - tuvo importante desarrollo. En la década de 1890 vendía moledoras de su fabricación a bodegas de Mendoza y SanJuan, es decir que abastecía un ámbito regional amplio. Esta empresa desapareció bien entrado el siglo XX.

En la primera década del siglo XX se inició, además, la adaptación de equipos importados a la realidad local y el desarrollo de nuevos productos, aunque no puede hablarse de un fenómeno generalizado. Se construían y adaptaban calderas tubulares, filtros paravinos, mezcladores de orujo, rectificadores continuos y sistemas de refrigeración. Estos últimos eran una respuesta al clima de Mendoza, con veranos más cálidos que los europeos, pero también representaron una innovación para servir a numerosas bodegas que se iban dotando de una gran capacidad de elaboración y prenunciaban el gigantismo que caracterizaría al modelo vitivinícola mendocino.

Esta etapa es muy importante porque muestra que se había producido con relativa rapidez un proceso de asimilación tecnológica, esencial para poder adaptar o diseñar nuevos productos, lo que en definitiva abriría paso al futuro desarrollo de industrias proveedoras del sector 
vitivinícola nacional y otros sectores agro industriales. En efecto, durante los años posteriores al Centenario se fue afianzando la industria local de equipo para bodegas, que incluía, como novedad, la fabricación bajo licencia de maquinarias complejas, italianas y francesas. Los talleres de Pescarmona y Rousselle, entre otros, fueron pioneros de la industria proveedora de bienes de capital para los sectores de transformación de materia prima agrícola. Sin embargo, este proceso no fue generalizado y la agroindustria continuó adoptando tecnologías de modo pasivo.

Los bienes de capital importados, directamente vinculados con la elaboración de vinos, procedían de países europeos de larga tradición vitivinícola (Francia, Italia, Alemania y España, en ese orden), en tanto que los equipos energéticos que permitirían la mecanización de las bodegas, provenían de Inglaterray, en menor escala, de Estados Unidos y de Alemania. Es decir que algunas economías industriales proveyeron equipamiento de alta tecnología de aplicación general y consumo mundial, como motores y calderas, en tanto que otros países industrializados, con una larga trayectoria en la elaboración de vinos enviaron equipos destinados a mercados específicos. Unos y otros,junto al transporte ferroviario y al decisivo aporte inmigratorio, contribuyeron a configurar el espacio productivo vitivinícola mendocino, con características propias, aunque con improntas de otras latitudes. Construido en muy corto tiempo, este espacio saltó las etapas evolutivas que caracterizaron a otras regiones del mundo, pasando del sistema de tradición colonial a una agroindustria con equipamiento transplantado sin aprendizajes previos y sin una masa crítica de trabajadores y empresarios portadores de una verdadera cultura de la vid y el vino.

No obstante 10 expuesto, puede decirse que no hubo posibilidad de otro resultado. La acelerada modernización fue cuantitativa, tanto en la fase agrícola como en la industrial, y modeló un sistema productivo de masa, con vinos de baja calidad, sin tipos definidos, con toda la estructura orientada a la gran producción: enormes paños de viñas, bodegas gigantescas y, en el caso de los pequeños productores de uva o vino, el objetivo único y excluyeme era producir lo máximo y venderlo cuanto antes; aunque la urgencia del viticultor se justificaba, además, en la necesidad de vender la uva en el tiempojusto antes de su natural deterioro. En este sentido, debe destacarse que la escasez de capital fue un factor de significativa importancia en la estructuración del modelo, pues eran contadas las bodegas que podían hacer una cuidadosa elaboración 
y estacionar sus vinos dos o más años para expender luego un producto de buena calidad; el grueso de las empresas debían realizar sus caldos cuanto antes para obtener el retorno que les permitiría reiniciar el ciclo productivo.

Los comerciantes extrarregionales (Buenos Aires, Rosario) desempeñaron un rol importantísimo en la orientación masiva del modelo, al menos basta los primeros años de este siglo, pues con un enorme poder de compra concentrado, frente a una oferta múltiple de infinidad de bodegas pequeñas y medianas, exigían vinos gruesos, de mucho cuerpo y color, alcoholizados, con la finalidad de estirarlos con agua o mezclarlos con vinos elaborados con pasas o cortarlos con caldos europeos. Cierto es, además, que las franjas más importantes del mercado, compuestas por sectores populares, no demandaban calidad sino precios bajos. Sólo un lento proceso de maduración de la industria local - encabezado por las grandes empresas que fueron asumiendo la comercialización de sus productos - produjo una mejora cualitativa, aunque la hegemonía de los vinos comunes destinados exclusivamente al mercado interno se mantuvo hasta la crisis que comenzó en la década de 1970 ,cuya profundidad ha dado lugar a radicales transformaciones, aún en curso, aceleradas por la denominada globalización económica (Furlani de Civit et al, 1991 y 1996;Richard-Jorba, 1998).

\section{El desarrollo agroindustrial}

Los resultados del proceso reseñado fueron óptimos por lo menos hasta 1910 , pese a algunas crisis. El capital mercantil había cedido paso al capital productivo y se desarrollaban los mercados de trabajo y de tierras. La expansión urbana acompañaba una creciente complejización económica manifestada en incipientes procesos de industrialización inducidos o derivados de la bodega (Pérez Romagnoli, 1995 y 1997) y en la ampliación del sector servicios.

El desarrollo territorial del viñedo tuvo una velocidad sin parangones en la historia del espacio productivo local.En efecto, el empadronamiento de viñedos en producción (tradicionales) realizado por el gobierno en 1883 , arrojó 1.486 explotaciones que abarcaban 2.788 ha, con una media de apenas 1,8 ha. Con las leyes promocionales, como fuera mencionado, se implantaron en las dos últimas décadas del siglo más de 17 mil ha de viñedos modernos distribuidos en casi 3 mil emprendimientos, con una media de 7,4 ha por finca. E1 $62 \%$ de las explotaciones y el $75 \%$ de la superficie vitícola estaban concentradas, en 1900 , en la Zona 
Núcleos, desde la cual partieron las ondas de difusión hacia el resto de la Provincia, con el ferrocarriljugando - como se ha mostrado - un papel clave en este proceso. En 1911, más de 53 mil ha de viñedos cubrían los oasis y un marcado desarrollo del cultivo se manifestaba en el oasis Sur (San Rafael), conectado por los rieles desde 1903. Para mediados de siglo,los viñedos se extendían sobre 108.347 ha y el tamaño medio de las explotaciones alcanzaba 8,3 ha (Zamorano, 1959).

La instalación de las bodegas que irían conformando el sistema agroindustrial, aunque con retraso y en menor medida de lo deseable, acompañó al viñedo. En 1887, se registraron 420 bodegas, muy pequeñas, artesanales, número que se amplió a 1.084 en 1899 , descendiendo a 1.043 en 1910-1911, como consecuencia de un lento proceso de maduración del sector. La diferencia no es sólo de cantidad de establecimientos; la modernización, ya descripta, estaba instalada y se desarrollaban las grandes bodegas - - para los cánones de la época - tecnificadas, con elaboraciones superiores a $10 \mathrm{mil} \mathrm{Hl}$ o las muy grandes, con capacidad de 50 mil o más H1. Aquellas eran 13 en 1899 y 47 en 1910; estas últimas, 2 y 4 entre los mismos años. En la década del 1900 comenzarían a aparecer sociedades anónimas - muy pocas - y, en algún caso, se incorporó capital extranjero. La elaboración de vinos creció exponencialmente: 58,9 mil Hl en 1888 , 926 mil en 1899 y alrededor de 3 millones al comenzar la segunda década de este siglo, momento en que los precios eran remunerativos y la producción se colocaba sin contratiempos.

Las nuevas bodegas se incorporaron al paisaje, modelándolo al compás de la gravitación del ferrocarril, factor de innegable incidencia en la localización de las fábricas. Iniciado el siglo XX, los casos más contundentes de la intimidad bodega-ferrocarril lo constituyeron las e mpresas que incorporaron cortos ramales que, desde las vías principales, ingresaban a las bodegas optimizando las operaciones de carga de vinos y descarga de equipos, envases, drogas, etc. Entre otras, este sistema fue implementado por Arizu, Barraquero, El Globo, Giol, La Superiora, Santa Ana,Tomba, etc. (Richard-Jorba y Pérez Romagnoli, 1994).

Las políticas de promoción del viñedo iniciadas por el Estado tuvieron otros resultados. Por una parte, la élite provincial, dedicada anteriormente

\footnotetext{
${ }^{5}$ Se ha denominado Zona Núcleo de difusión de la vitivinicultura moderna, al espacio que circunda la capital mendocina, integrado por los departamentos de Las Heras, Godoy Cruz, Guaymallén, Maipú y Luján de Cuyo, además de la ciudad de Mendoza (Richard-Jorba, 1992).
} 
a la producción de alfalfa-cereales y a la exportación ganadera, se acopló al nuevo modelo productivo y concentró significativamente la propiedad vitícola. Entre 1881 y 1900 , treinta grupos familiares de esa élite eran propietarios del $15 \%$ de las explotaciones y el $31 \%$ de la superficie vitícola desarrollada con promoción fiscal. La mayoría de esas familias invirtió capitales en la industria del vino, constituyéndose en núcleo de una burguesía productora que, junto con agentes provenientes de la inmigración (temprana y masiva), integrarían un empresariado regional y realizarían una importante acumulación de capital, conformando un polo de poder económico y político de fuerte y prolongada presencia en la vida provincial. Por otra parte, la actividad vitícola determinó la formación de una clase de pequeños y medianos propietarios, mayoritariamente inmigrantes, que tendría incidencia en la ampliación de los estratos medios de la sociedad mendocina ${ }^{6}$. Hacia 1900, las explotaciones menores de 10 ha alcanzaban al $83,2 \%$ del total de viñedos promocionados, cubriendo el $37,4 \%$ de la superficie cultivada con vid'. Muchos de estos pequeños productores integraron la etapa industrial, con bodegas de escasa capacidad de elaboración (menos de $5.000 \mathrm{H} 1$ ) y equipamiento de baja complejidad o inexistente ${ }^{8}$. En 1910 representaban alrededor del $90 \%$ del total de establecimientos en operación y su oferta dispersa era adquirida en parte por las grandes firmas y, mayoritariamente, por comerciantes del Litoral y Buenos Aires, es decir por una demanda relativamente concentrada, formándose así el denominado mercado de traslado.La dependencia y debilidad de estos productores (que incluyó,

- Los cambios económicos generaron transformaciones sociales y, gradualmente, la antigua unidad entre poder político y económico tendió a disociarse. Paralelamente, el desarrollo de partidos políticos nacionales se sumó al proceso local para diluir el poder político de la élite criolla e incrementar el poder nacional.

De los 2,9 mil viñedos con promoción fiscal, 758 (26\%) tenían menos de 1 ha; $664(23 \%)$ cubrían de 1,01 a 2,5 ha y 531 (18\%) ocupaban el estrato de 2,51 a 5 ha. El restante $16 \%$ eran 462 propiedades de 5,01 a 10 ha.

"En 1899 el $76 \%$ de las bodegas registradas elaboraban menos de 500 Hl de vino. Para 1910 , ese valor se había reducido al $60 \%$. Si se consideran producciones de hasta $1.000 \mathrm{HI}$, en los dos años indicados, los establecimientos representaron el 87 y $70 \%$ respectivamente (Pérez Romagnoli y Richard-Jorba, 1994).

El vino era enviado a granel a los mercados de consumo y fraccionado allí por los comerciantes, con sus marcas propias. Este mercado existe todavía, aunque en retroceso, porque las exigencias de genuinidad y calidad de los caldos van imponiendo, gradualmente, el envasado local para los vinos de mesa, y se procura extender la denominación de origen para los vinos finos y especiales. El mercado de traslado mantiene su vigor en las compras entre bodegas. 
al menos hasta 1900 , a los grandes bodegueros) ante los compradores era manifiesta y fue motivo de no pocos conflictos frente a precios y formas de pago fijados arbitrariamente.

A principios de la década de 1950 , se mantenían en general los valores de distribución de explotaciones y superficies vitícolas. Las fincas menores de 10 ha representaban el $84,5 \%$ y ocupaban el $30 \%$ de las extensiones dedicadas a la vid (Zamorano, 1959). En comparación con los comienzos de siglo había un aumento relativo en las explotaciones y una disminución en las superficies controladas, lo que indica un mayor grado de concentración del factor tierra. Persistía, no obstante, la clase de pequeños propietarios bien sostenida aún por la rentabilidad de sus viñedos. El régimen de "contratos" ${ }^{\circ}$, bajo el cual había numerosas explotaciones contribuía, por su parte, a una mejor distribución social del ingreso (Rodríguez, 1968).

A lo largo del siglo y hasta la década de 1970, el modelo productivo vitivinícola no varió, antes bien, acentuó muchos de sus rasgos negativos: gran producción de baja calidad - salvo puntuales excepciones destinada a un mercado nacional altamente protegido y fuerte intervención estatal - esta vez mayoritariamente nacional - para atenuar numerosas y reiteradas crisis ${ }^{1}$. En ocasiones, el granizo y la helada

- La figura del "contrato" tenía un actor central, el "contratista", a cuyo cargo estaba la explotación de una finca o de parcelas ( 10 a 15 ha) de grandes propiedades. Recibía por su trabajo un salario y una participación en la producción, con porcentajes variables, aunque mayoritariamente situados en torno al $20 \%$. $\mathrm{Nu}$ merosos contratistas, en el pasado, accedieron a la propiedad de la tierra y, en menor medida, llegaron a ser titulares de empresas vitivinícolas grandes, de modo que el contrato fue, en muchos casos, un medio importante de movilidad social ascendente. Este actor comenzó a difundirse a principios de siglo. En 1968, el $\mathbf{3 3 , 7 \%}$ de los viñedos y el $\mathbf{4 1 , 8 \%}$ de la superficie vitícola eran explotados por el régimen de contratos.Valores similares $(32,2$ y $44,7 \%)$ se registraban todavía en 1985 (INV, 1969-b-:42 e INV, 1987:13).

Por ejemplo, como consecuencia de la depresión de los años treinta, el Gobierno Federal creó la Junta Reguladora de Vinos para intentar controlar los efectos de la sobreoferta y las caídas del consumo mediante la erradicación de viñedos y la destrucción de vinos. Se erradicaron en Mendoza 17 mil ha de viñas. De 100.619 ha existentes en 1936 se pasó a 83.605 en 1938, manteniéndose este valor hasta 1944 inclusive (Rodríguez, 1968). Histórica paradoja: casi las mismas hectáreas implantadas con promoción estatal en las dos últimas décadas del siglo XIX, fueron destruidas por el mismo poder, aún cuando uno fuera provincial y el otro federal. El crecimiento económico que experimentaba el País por medio del modelo de industrialización por sustitución de importaciones, determinó una nueva etapa de crecimiento del viñedo desde 1945, que se prolongó hasta mediados de la década de 1970. 
moderaban la oferta de uvas y contribuían a equilibrar la ecuación económica entre producción y consumo, manteniendo aceptables niveles en la rentabilidad de empresas grandes y medianas capitalizadas, en las etapas agrícola, industrial y comercial; pero en otras oportunidades se desataron crisis más graves, que implicaron erradicación de viñedos y destrucción de vinos o cambios forzados, como la fabricación de mostos concentrados o la destilación de caldos para obtener alcohol, la fijación de cupos de comercialización, adquisición de excedentes por parte del Estado, etc. Precisamente, el Gobierno de Mendoza incorporó a su patrimonio la gran empresa vitivinícola Giol en 1954, innovación institucional que hacía aparecer la figura del Estado-empresario. El objetivo fundamental era regular el mercado de vinos y defender a los viñateros sin bodega. Por otra parte, el Instituto Nacional de Vitivinicultura, organismo federal, establecía políticas para el sector en todo el país, controlaba la genuinidad de los caldos, determinaba cupos de producción y comercialización, etc.

\section{La reconversión globaiizadora: nuevo modelo o evolución?}

\section{Globalización y nueva división internacional del trabajo}

Desde los años setenta, la crisis del modelo fordista de acumulación inició procesos de cambios en la economía mundial que conducirían a la denominada globalización, fenómeno caracterizado, entre otras cosas, por la autonomía del capital financiero, el papel preponderante de las empresas transnacionales, la pérdida de poder económico del Estadonación, la desregulación de los mercados, las nuevas formas que adquiere la división internacional del trabajo, la extranjerización de las economías nacionales, etc. ${ }^{2}$.

La globalización - y el conjunto de fenómenos asociados - constituye una transformación cualitativa del régimen de acumulación que modifica al instaurado después de la Segunda Guerra y cuyo núcleo está todavía integrado por los Estados que forman el denominado G-7. Se trata de modificaciones en los principios que gobiernan la pro-

12 Hay sobreabundante bibliografía que estudia estos procesos, con diversos abordajes y variados enfoques ideológicos. Entre los geógrafos, cabe mencionar a Milton Santos (1996) y David Harvey (1998). Otros destacados trabajos corresponden a Aido Ferrer (1996),José María Vidal Villa (1995), Naum Minsburg y Héctor Valle (1994). 
ducción y la distribución de la riqueza, entre los individuos y los Estados (Letourneau, 1993).

Entre las características sobresalientes de este nuevo régimen se destaca la movilidad creciente e irrestricta del capital - que paralelamente se concentra y se centraliza geográficamente - y, en menor medida, la movilidad física que adquiere una categoría privilegiada y altamente valorada de profesionales, investigadores y ejecutivos con formación de gran nivel de especialización. Por otra parte, se procura restringir al máximo la migración de trabajadores.

La riqueza es creada y repartida en torno a las fases de concepción, fabricación y comercialización de bienes y servicios que, en la medida de lo posible, tengan alto valor agregado. Es decir que el centro económico ha dejado de estar puesto en la fabricación masiva de objetos vulgares que son ofertados a un máximo de consumidores situados dentro de un espacio dado (nacional); se basa actualmente en la concepción y producción de bienes complejos, con muy alta relación capital/trabajo (capital-intensivos), para ser vendidos a clientelas especializadas distribuidas en el mundo entero (Letourneau, 1993).

Desde una perspectiva espacial puede decirse, en términos generales, que se construye una nueva división internacional del trabajo, entre espacios donde se centraliza el capital y en los cuales se concibe y se desarrolla el conocimiento y la tecnología y espacios reducidos a la condición de factorías y mercados de consumo. Las excepciones muy pocas - comprenden algunos países asiáticos (Israel, Corea del Sur, Taiwan, India, China) y latinoamericanos (Brasil) con fuertes inversiones estatales en Ciencia y Tecnología. Los capitales productivos transnacionales que invierten en determinados espacios, cuando demandan bienes y servicios de alta complejidad lo hacen - habitualmente - a sus países de origen, de modo que allí se refuerza y retroalimenta el proceso de acumulación de capital y desarrollo tecnológico y, paralelamente, se debilita en el territorio factoría.

\section{Vitivinicultura y globalización}

Pese a numerosas evidencias que indicaban la profundización de situaciones críticas para el sector, desde 1970 continuó en Mendoza la plantación de nuevos viñedos de baja aptitud enológica, fomentada indirectamente por una legislación nacional (Ley 18.905/70) que propiciaba - con loable intención - integrar las diversas etapas de la vitivinicultura, diversificar sus productos y colocarlos en los mercados externos. Los créditos y las desgravaciones impositivas no dieron re- 
sultados convincentes. Se sumó a esta política, la Ley 20.954/74, que promovió la incorporación de zonas áridas a la actividad agropecuaria mediante riego con aguas subterráneas. Las inversiones surgirían de desgravadones tributarias nacionales, implicando, en consecuencia, un alto costo fiscal. Estas leyes dieron lugar al desarrollo de nuevas plantaciones, mayoritariamente de cepajes comunes, localizadas sobre todo en la periferia de los oasis y caracterizadas por su gran tamaño (de cientos de ha hasta más de mil) aunque,justo es decirlo, hubo casos de aplicación de tecnologías avanzadas e integración industrial, concretadas por tradicionales empresarios del sector, pero además por agentes provenientes de otros sectores económicos y de otras regiones (Furlani de Civit et al, 1991). Las condiciones requeridas para estos emprendimientos favorecieron a empresas con fuerte disponibilidad de capital y no tuvieron incidencia sobre los pequeños y medianos productores.

Difícilmente estas medidas hubieran podido cambiar el statu quo, porque para ello se requiere esencialmente la aparición de nuevas actitudes políticas y empresariales. Entre las primeras, no existió la necesaria coherencia de una política de Estado (federal y provincial) que definiera prioridades y objetivos; y dispusiera los medios para cumplirlos e implementara simultáneamente un estricto seguimiento, con premios y castigos según los resultados. En el mundo empresario, siguió dominando la mentalidad del viejo modelo, característica por lo demás de buena parte del empresariado nacional, esto es, rentismo, mantenimiento de un capitalismo prebendario, escaso interés por la innovación, adaptación pasiva y tardía de tecnologías generadas en otras geografías y poca predisposición para conquistar nuevos mercados. Salvo puntuales excepciones, sólo se procuraba exportar cuando el mercado nacional se retraía colocando mayoritariamente los excedentes de vinos comunes y mostos concentrados ${ }^{13}$.

Como no podía ser de otra manera, esa expansión fue inorgánica y desarticulada, con consecuencias letales para la vieja estructura económica. La inercia condujo el proceso por algún tiempo, pero se detuvo

13 Por ejemplo, entre 1937 y 1946 se exportaron entre 5.000 y 20.000 Hl de vino argentino, mayoritariamente desde Mendoza. Desde fines de los años 40 comenzó un descenso: $9.500 \mathrm{HI}$ en 1948; 406 en 1952; 2.700 en 1963 y un repunte en 1968, con 29 mil HI (INV, 1969-a-:191). Como se aprecia, se trata de volúmenes erráticos, demostrativos de la inexistencia de una política exportadora por parte del Estado y de los empresarios. En la década de 1980,1a crisis de la vitivinicultura obligaría al cambio. 
hacia 1978 y, desde mediados de la década del ochenta, comenzó una retracción sostenida de las superficies vitícolas por diversas situaciones, entre las que sobresalía el descenso del consumo de vinos (de 86 litros en 1968 a 60 en 1986) ${ }^{14}$. En efecto, desde un máximo histórico de 252.928 ha en 1978 ,el viñedo perdió posiciones y en 1987 se registraban 190.982 ha. El descenso continuó hasta comienzos de los años noventa, cuando alcanzó poco más de 145 mil ha, aunque aparecía entonces una tendencia a la recuperación del cultivo pero con características diametralmente opuestas a las vigentes desde la modernización de fines del XIX, porque comenzaban a desarrollarse nuevas explotaciones en las que se priorizaba y valoraba la plantación de cepajes finos. De ningún modo ha sido éste un proceso lineal, porque en paralelo con los nuevos viñedos, se produjeron erradicaciones, abandonos o regresión por abandono encubierto de antiguas plantaciones, estimados en alrededor de 40 mil ha (González Valverde, 1986, citado por Gutiérrez de Manchón, 1996), pero también reconversiones de viñedos de masa a varietales finos, que han contado con apoyo estatal. Las erradicaciones y abandonos corresponden en general a explotaciones pequeñas en las cuales la inversión en tecnología es de difícil concreción por indisponibilidad de capital o bien, porque no se justifica en términos de rentabilidad. Se acentuaba con ello la tendencia a una mayor concentración de la propiedad de la tierra. Además la figura del contratista desaparecía rápidamente, reemplazado por administradores, de manera que este actor, semi-empresario, se transformaba en asalariado, reforzando la distribución regresiva del ingreso ${ }^{15}$.

El retroceso del viñedo no ha respondido sólo a causales económicas. Factores ambientales han motivado el abandono de zonas marginales

14 Este descenso ha continuado y se sitúa en alrededor de 40 litros actualmente. Es atribuido a diversos factores, entre los que destacan la pérdida de poder adquisitivo en sectores mayoritarios de la población, el temor generado por falsificaciones de vinos comunes con productos tóxicos, el cambio en los gustos del consumidor, que se vuelca cada vez más hacia la cerveza y bebidas gaseosas, etc. Paralelamente, crece sostenidamente la demanda de vinos finos.

is En 1998, la plantilla de trabajadores del sector ascendía a un total aproximado de 20.000 personas, de las cuales, un $30 \%$ trabajaría en bodegas y el resto en la fase agrícola. Durante la vendimia se agregan unos 5 mil trabajadores temporarios (Fuente: información suministrada al autor por $e_{i}$ Instituto de Desarrollo Rural de Mendoza, sobre la base de estimaciones de la Federación de Obreros y Empleados Vitivinícolas-FOEVA). No existen datos sobre la cantidad de "contratistas" de viña que aún permanecen en el mercado laboral. 
poco productivas que fueron incorporadas en etapas de auge vitivinícola. Intervienen además otros procesos, como la expansión de la conurbación mendocina que ha ido desplazando y haciendo desaparecer la antigua Zona Núcleo de difusión de la vitivinicultura moderna, reemplazando el suelo agrícola por usos residenciales, industriales, de servicios, fenómenos que también caracterizan al Oasis Sur.

Entre las grandes transformaciones que registra la vitivinicultura mendocina, la privatización de Bodegas y Viñedos Giol Sociedad del Estado, concretada por el Gobierno de ta provincia, marcó un hito en 1o referente al retiro del Estado como empresario ${ }^{16}$. No obstante, estas transformaciones recientes se generalizan a partir de la apertura irrestricta de la economía argentina y la desregulación de la actividad desde fines de 1991, y se manifiestan — entre otros aspectos —, en una fuerte concentración de capitales (cultivos y bodegas), lo que marca una diferencia con la primera modernización porque está generando un proceso de integración vertical de las empresas. La concentración, además, está conduciendo rápidamente a una conformación oligopólíca del sector ${ }^{17}$. Los cambios conducen, asimismo, a una reorientación productiva hacia vinos finos y champagnes, y hacia la exportación, así como a la incorporación de tecnología extranjera de punta (agrícola e industrial, control de calidad, marketing, etc. ${ }^{18}$. En efecto, para 1996 la

${ }^{16}$ Li gran bodega Giol fue fundada a fines del XIX por inmigrantes italianos $\mathrm{y}$ suizos y, como se ha dicho, expropiada por el Estado provincial en los años 1950 para regular el mercado de vinos y proteger a los pequeños viñateros sin bodega. Los procesos de desregulación promovidos por la ideología liberal desde la década de 1980, sumados a persistentes déficits de la empresa, condujeron a su privatización, quedando en manos de una Federación de cooperativas (FECOVITA) Esta Federación agrupa 37 cooperativas que reúnen unos 5 mil productores. Controla alrededor del $15 \%$ del mercado nacional de vinos (comunes y finos).

"Alrededor de ochenta bodegas encabezan la producción de vinos de calidad y son las que están en condiciones económicas de continuar invirtiendo en tecnología y gestión (informe de Martelo Sivera, LOS Andes Económico, 7-3-1999). En este segmento, por tratarse de productos con alto valor agregado, la buena rentabilidad empresaria permite - todavía - la coexistencia de un espectro de grandes y medianos productores. Sin embargo, cinco bodegas de ese conjunto (el 6\%) controlan el $40 \%$ del mercado de vinos finos $y$, al menos dos de ellas, pertenecen a un fondo de inversión transnacionai. El fenómeno oligopólico se acentúa en el mercado interno de los vinos comunes o de mesa, controlado en un $80 \%$ por seis empresas (dos son cooperativas). Dos de estas firmas cubren el $50 \%$ de este mercado.

${ }^{1 s}$ La tecnología de riego presimzado, por ejemplo, elimina la tradicional acequia, aporta sólo el agua necesaria para cada planta y evita el lavado o la salinización de 
superficie con viñedos alcanzaba 143.764 ha y la producción de uvas finas representaba el $35 \%$ según una revista especializada, aunque en departamentos caracterizados por la excelente aptitud de sus suelos para la viticultura estos cepajes son dominantes $(66 \%$ en Tupungato y $70 \%$ en Luján) (Vinífera, 1997:30). E1 avance del viñedo fino va acompañado de la aplicación de nuevas tecnologías de riego, sistemas fitosanitanos de reciente desarrollo, introducción de clones libres de virus, cambios en la conducción de las plantas, mallas protectoras contra el granizo, etc. Y si bien se reconvierten antiguas explotaciones vitícolas, el mayor desarrollo se observa en nuevos terrenos donde, sin tareas de nivelación y con la previa eliminación de la vegetación autóctona y construcción de la infraestructura de riego y conducción, se implantan las cepas de alta calidad enológica. El Valle de Uco \{Tunuyán y Tupungato) ha sido el espacio preferido para estos nuevos emprendimientos, que avanzan sobre el piedemonte y se ubican por encima de los 1.100 $\mathrm{m} \mathrm{s} / \mathrm{n} / \mathrm{m}$.

La inversión en la industria, sea mediante la construcción de nuevas bodegas (Bodega Bianchi para champagne, Viña Morandé, Flichman, etc.) o el reequipamiento de las existentes (Chandón, Esmeralda, Goyenechea, Lagarde, Leoncio Arizu, Norton, Orfila, Santa María, Suter, etc.), suma varios millones y persigue el objetivo de mejorar la calidad y conquistar nuevos mercados o ampliar la presencia en franjas ya consolidadas del interno o el internacional (Llaver, 1997). El resultado se refleja en la producción de vinos denominados de "alta gama"y en un fuerte crecimiento de los caídos de precios intermedios y otros relativamente bajos (los llamados "finitos"). La etapa comercial se orienta crecientemente hacia la exportación ${ }^{19}$, porque los nuevos grupos em-

los suelos, además de ahorrar el valioso y escaso recurso hídrico. Aunque la inversión necesaria no es accesible para cualquier productor, este sistema avanza rápidamente en Valle de Uco (departamentos de Tunuyán, Tupungato y San Carlos); y entre 1994 y 1998 ha llegado a representar el 8\% de las superficies irrigadas de esa zona. La conducción de las plantas en espaldero y nuevas técnicas de podajunto con la protección antigranizo, tienden a asegurar buenos niveles productivos y alta calidad. Algunas explotaciones han comenzado a mecanizar la cosecha. Se introducen también cepas producidas en viveros franceses y califormanos. En la fase industrial, la nueva modernización incluye tanques de acero inoxidable, técnicas de frío y el empleo de gases inertes para mejorar sabores e impedir el deterioro de los caldos, es decir, se controla la fermentación y se conservan aromas y colores (Los Andes Económico, 13-9-98, 8-11-98 y encuestas propias).

${ }^{19}$ A mediados de la década de 1970 , como efecto de la crisis señalada, comenzó a 
presados que se instalan en la Provincia cuentan, en general, con una inserción previa en el mercado externo. Las empresas de capitales locales o nacionales intentan seguir ese camino. Por supuesto, no se descuida el desarrollo del mercado interno, en el que se observa un paulatino desalojo de los vinos comunes. En todo esto hay un destacable accionar conjunto, gubernamental y empresarial, es decir una forma de articulación entre el Estado y las empresas para facilitar la concurrencia al denominado "mercado global"

Todos estos cambios, si bien mejoran la calidad de los vinos — y esto se comprueba en los numerosos premios internacionales obtenidos por bodegas de Mendoza - generan otros problemas. En efecto, como consecuencia de los fenómenos que caracterizan la "globalización", se está produciendo un proceso de transferencia de empresas líderes de capitales locales (Balbi, Cavas de Santa María,Etchart, Flichman, Mardns, Norton, Premier, Santa Ana,Toso, Weinert, Nieto y Senetiner, por mencionar algunas) a grandes grupos extraprovinciales o, más frecuentemente,

buscarse una salida exportadora, sobre todo de vinos, aunque también de subproductos (mostos concentrados, alcohol, ácido tartárico, etc.), pero se mantenían los volúmenes erráticos. Si en 1978, por ejemplo, se exportaron $675 \mathrm{mil}$ Hl de vinos argentinos, al año siguiente sólo se vendieron $87.800 \mathrm{Hl}$ y en 1985 , se enviaron al exterior 195.800 HI. Hasta ese año, aunque dominaban los vinos comunes, no había una tendencia definida. En 1978 y 1985, los caídos de mesa representaron e; $90 \%$ de las ventas; entre 1979 y 1981, ese porcentaje varió entre el 75 y el $55 \%$. El cambio parece sobrevenir con posterioridad. En 1986 se exportaron $198.300 \mathrm{HI}$ de los que un $79 \%$ correspondieron a vinos de mesa (99\% originado en Mendoza) y un $21 \%$ a finos y especiales (95\% en promedio, de Mendoza) (INV, 1987). En los 90, con la desregulación y la transferencia de empresas a capitales extranjeros o extraprovinciales, se ha reforzado la tendencia hacia la producción y exportación de caldos de calidad. En 1998, por caso, la Argentina exportó 538.800 Hi de vinos finos, $94 \%$ de los cuales fueron elaborados en Mendoza. En cambio, de los 540.900 Hl de vinos comunes vendidos al exterior, sólo el $67 \%$ correspondió a caldos locales y el resto a otras provincias, principalmente San Juan. En 1999 las exportaciones mendocinas de vinos finos descendieron un $22,4 \%$ y las de vinos comunes un $18,8 \%$ respecto del año anterior (Los Andes Económico, 6-2-2000).

20 En noviembre de 1994, los gobiernos de Mendoza y San Juan firmaron un tratado creando en el ámbito de cada una de esas provincias, el FondoVitivinícola, con el carácter de persona jurídica de derecho público no estatal y con el objeto de promover la vitivinicultura y las exportaciones de sus productos. Los recursos del Fondo provienen de aportes estatales y de los productores privados. La Fundación Pro Mendoza, entidad que cuenta con apoyo estatal y empresario, organiza grupos de bodegueros y salen al exterior a ofrecer su producción en forma conjunta. 
transnacionales ${ }^{21}$, lo que no sólo traslada a otros espacios geográficos parte del poder de decisión económica sobre la región, sino que se deprime la industria local proveedora de equipo y las actividades de investigación y desarrollo asociadas que pueden fortalecerla. El capital transnacional interrumpe, en cierta medida, los antiguos encadenamientos productivos regionales, algunos de los cuales, como se ha visto, se originaron en ios comienzos de la primera modernización, aunque el desarrollo efectivo de la industria proveedora de máquinas y equipos se produjo en una etapa de consolidación desde la década de 1940 (Pérez Romagnoli, 1997), es decir, cuando avanzaba el modelo de desarrollo industrial por sustitución de importaciones. Esa interrupción se genera al incorporarse al proceso productivo parte importante de las tecnologías y equipos provenientes en su mayoría de los países de origen de algunos de los nuevos inversores; y el empresariado local hace otro tanto, siguiendo una lógica de comprar lo mejor — tecnología de punta - con precios y financiación que difícilmente puedan obtenerse en el País². Por supuesto, este proceso disminuye considerablemente la acumulación de capital local que distinguió a Mendoza en las etapas anteriores

Entre los grupos que han adquirido empresas en funcionamiento pueden mencionarse: Fondo DLJ, de EEUU, en sociedad con un grupo local; Santa Carolina (Chile); Allied-Domecq y Cimba (Gran Bretaña); Seagram (Canadá-EEUU); Sogrape (Portugal);Swarosky (Austria);Agrícola y Comercial Lourdes (Chile); Pernod Ricard (Francia); Bodegas Hispano Argentinas (España), etc. Los grupos nacionales más importantes son Pérez Companc y el Fondo Inversor Sabores Argentinos (Grupo Soldad); y de los locales, Citena y Peñaflor (integrado también por el Fondo DLJ).Las nuevas inversiones incluyen empresas de Chile (Vina Santa Rita, Concha y Toro, Viña San Pedro, Viña Morandé); de España (Bodegas Hispano Argentinas, Cava Codorniú); de Francia (Chandon, Fabre Montmayou, Lurton); de EEUU (Kendall Jackson), etc. (Fuente: base de datos del Autor).

Esta estrategia empresarial no es de ninguna manera cuestionable. La financiación bancaria en la Argentina es altamente onerosa, con plazos relativamente cortos y altísimos intereses para un país sin inflación. La Unión Europea, en cambio, promueve sus exportaciones industriales con créditos de bajo interés, plazos considerables y adecuados períodos de gracia. Si bien hay un beneficio notorio para la empresa en cuanto agente económico, debe señalarse que la adquisición de maquinarias y procesos técnicos importados, refuerzan la tendencia hacia una nueva división internacional del trabajo, es decir, una especialización productiva del espacio agrícola provincial sustentada en la incorporación pasiva de tecnología extranjera. En este sentido, habría una especie de "retorno a las fuentes", es decir, al modo en que se produjo la primera modernización, aunque con una diferencia esencial: hoy "el conocimiento" no puede ser imitado o copiado porque está protegido internacionalmente. 
de la vitivinicultura y el tecnodesempleo, que normalmente sigue a cualquier modernización, agudiza los problemas de exclusión social

Se reproducen así en la Provincianos procesos que registra la Argentina en su conjunto: el retiro de importantes sectores del empresariado de buena parte de las actividades productivas, por temor o imposibilidad de competir frente a las transnacionales, y su reinserción en nichos económicos presentes aún en sectores del comercio y otros servicios, visualizados como más seguros, con mercados relativamente cautivos. Este fenómeno, que caracteriza a buena parte de América Latina, implica el reemplazo de una élite económica con poder hacia el interior nacional o regional, por otra integrada en corporaciones con orientación global y conducidas desde el exterior (Sklair, 1992; Richard-Jorba, 1998). Se reiteran entonces, caracteres de rentismo y de escasa capacidad de innovación, es decir, ausencia del empresario schumpeteriano (Schumpeter, 1996) y el empresariado regional pierde poder y la capacidad de incidir sobre el Estado. No obstante, existen grupos empresariales locales o del resto del país altamente diversificados que,junto a productores medianos capitalizados, invierten en vitivinicultura ${ }^{23}$.

Es posible - y deseable - que estos actores avancen más allá de la actual rentabilidad del sector vitivinícola y promuevan, junto con el Estado, acciones e inversiones en ciencia y tecnología para recrear los encadenamientos productivos. De tal manera, se potenciará la industria local de equipos para bodegas y el desarrollo de procesos productivos para competir con quienes dominan hoy estos rubros en el mercado mundial. Una demostración de que el mercado es promisorio la constituye la instalación, en 1996, de T.I.A.Inox, subsidiaria de la italiana Oenotecno, para fabricar bienes de producción para bodegas que antes importaba. Obviamente, el camino no es producir conocimiento y tecnología desde un punto cero, sino comenzar por la adopción y la difusión de lo actualmente disponible en el mundo y, a partir de allí, innovar de acuerdo con las condiciones ambientales, económicas, sociales y culturales. Y es función del Estado contribuir a difundir la modernización tecnológica, particularmente entre los grupos de productores pequeños y medianos descapitalizados e imposibilitados de proveerse en "el mercado", a fin de evitar la formación de umbrales tecnológicos insalvables que los excluyan de la actividad económica.

\footnotetext{
${ }^{23}$ Los principales grupos son Cacena y Pescarmona, enere los mendocinos; y Pérez Companc, del resto del país. Hay también empresarios que están reinvirtiendo en el sector luego de la venta de sus antiguas firmas.
} 
Debe señalarse, sin embargo, que avanzar en esa dirección no es tarea fácil. El poder político local tiene muy escasa capacidad de intervención y de negociación para revertir las situaciones comentadas, no sólo ante al poder estatal nacional, sino ante el poder económico transnacional, porque la aceptación de la globalizacíón en el país se materializó sin la elaboración de una transición ordenada desde una economía protegida a otra desregulada que pudiera aprovechar las ventajas de la modernización y reducir en lo posible las consecuencias negativas. Y esto sucede porque también las dirigencias políticas han sufrido una mutación, abandonando concepciones centradas en el estado-nación e incorporando la "ideología de la globalización" como guía de su accionar, sin percibir que la "... inexistencia actual de organizaciones estatales supranacionaks (efectivamente soberanas) se revela como un signo de perduración de los espacios nacionales, y aunque en los hechos éstos estén sujetos a procesos de desestructuración siguen siendo un fenómeno característico de la evolución económica y política mundial" (Rapoport, 1997:39).

\section{Conclusiones}

Un breve repaso de lo expuesto, permite concluir que la primera modernización de la vitivinicultura a fines del siglo XIX condujo al desarrollo de una de las denominadas economías regionales de la Argentina, la región vitivinícola conformada por Mendoza y SanJuan, productoras de más del $90 \%$ de los vinos argentinos. Resultó ser un modelo atípico para la época, porque desde un punto de vista económico contradecía las leyes naturales de la ciencia económica finisecular. Gozó, en efecto, de promoción y protección en un mundo librecambista al cual se había integrado la Argentina. En este sentido, el modelo era semejante a los esquemas propios de la llamada industrialización por sustitución de importaciones (ISI) que caracterizó buena parte de este siglo. Ese modelo vitivinícola era, obviamente, fruto de una necesidad política y de una negociación imprescindible para consolidar al moderno estado-nación argentino e inaugurar un régimen capaz de asegurar la gobernabilidad del país (Botana, 1994). Aunque debe profundizarse la investigación, puede sugerirse que el modelo comenzó una larga crisis cuando afianzado el Estado nacional - las élites regionales perdieron poder y se nacionalizaron, insertas en partidos con conducciones centralizadas, que obligaron a cambiar antiguos sistemas de lealtades y diluyeron la capacidad de negociación de las regiones o provincias; tendencias éstas reforzadas por los largos períodos de gobiernos de facto. En los años 
1870 el modelo cayó por su propio peso, encerrado en un mercado nacional estancado, con la producción sujeta a sobreproducciones o subconsumo. El espacio estratégico nacional - la pampa húmeda concentra toda la atención del poder central, porque allí está el núcleo de la vinculación del País con el mundo en términos económicos y políticos, de modo que la consideración prestada a la vitivinicultura se daba siempre de manera coyuntural, sin llegar a soluciones estructurales. La propia dinámica de la crisis condujo al comienzo de cambios en el sector vitivinícola, anteriormente reseñados.

La transformación de la economía iniciada una década atrás con vistas a una nueva inserción del País en el contexto internacional significó un cambio profundo tanto en lo económico cuanto en lo social y político. Apertura irrestricta de la economía, desregulación de todas las actividades, modernización de las telecomunicaciones y de la infraestructura portuaria, desarticulación del sistema ferroviario, eliminación de las redes de protección social que habían caracterizado al Estado de Bienestar (flexibilización laboral, reducción de indemnizaciones, contratos de trabajo precarios, etc.). Este proceso desregulatorio obligó a acelerar la reconversión del viejo modelo vitivinícola iniciada a comienzos de los ochenta, transformándolo en una agroindustria orientada por la nuevas tendencias económicas: abandono de las commodities (vinos comunes) y producción de bienes con el mayor valor agregado posible, selectivos y destinados a ulereados no masivos (vinos finos, especiales, champagnes). Todo lo cual conduce hacia el dominio de los agribusiuess en sustitución de las empresas familiares, acompañado por un proceso en el que lo político se va subsumiendo en lo económico.

E1 viejo modelo se construyó, en buena medida, promoviendo la movilidad irrestricta del factor trabajo y recibiendo masivamente inmigrantes - calificados o no - para desarrollar los cultivos, las bodegas y las industrias conexas. Las nuevas condiciones abren camino hacia la excelencia vitivinícola pero dificultan el desarrollo industrial y están generando sentimientos xenófobos hacia el trabajador extranjero.

Al fuerte protagonismo del Estado - nacional y provincial - entre 1870 y 1970 , es decir de la política, se contrapone hoy la debilidad del compromiso estatal, reducido a una limitada aportación en la promoción del sector vitivinícola (propaganda, reintegros por exportaciones). La política se presenta así cada vez más subordinada a lo económico. En este sentido, no sólo perdió significación el Estado en la economía librada a la mano invisible del mercado - , sino en un rubro clave: 1a educación formal. La otrora preocupación gubernamental por formar 
recursos humanos capacitados para la buena evolución de las actividades económicas ha quedado al arbitrio de las empresas por ausencia del Estado en esa función indelegable, con el agravante de que una reciente investigación señala la "marcada debilidad en la capacitación del personal..." por parte de estos agentes económicos (Furlani de Civit et al, 1996: $130)$.

Para terminar, queda por responder el interrogante de si se asiste a la conformación de un nuevo modelo o si, por el contrario, sólo se trata de una evolución. En este último caso, habría sido un proceso de maduración, que hizo su experiencia fundacional en un mercado cerrado sobre el que se pusieron a prueba tecnologías o se ensayaron elaboraciones con vistas a imponer determinados tipos de vinos, para avanzar luego hacia la conquista de otros mercados. No parece haber sido éste el camino seguido - salvo excepciones. Cabe pensar entonces que se trata de un modelo nuevo que se va imponiendo globalmente desde las economías avanzadas del planeta, deseosas de capturar con su capitales porciones de cualquier mercado que ofrezca alta rentabilidad.Y en este sentido, Mendoza (también San Juan), ofrece adecuadas condiciones ecológicas para el cultivo de la vid, dispone de infraestructura y de establecimientos vinícolas de larga experiencia y trayectoria, con productos prestigiados en el mercado nacional y, en menor grado, en el internacional. También ofrece abundantes recursos humanos, profesionales y obreros, con salarios largamente inferiores a los de países industrializados. Es decir, una aptitud general de este espacio productivo que bien reestructurada y gerenciada puede llegar a constituir una enorme fuente de renta. Sin embargo, al perfilarse una nueva división internacional del trabajo, pareciera que en realidad revive lo viejo a escala internacional, aunque con un mayor protagonismo del capital transnacional por sobre los Estados; y lo "nuevo" que aparece a escala local y regional, podría tratarse sólo de una segunda modernización como mera estrategia adaptativa a las tendencias de un presente aún no concluido.

\section{Referencias bibliográficas y fuentes}

Acevedo, Edberto O. Investigaciones sobre el Comercio Cuyano. 1800-1830. Buenos Aires: Academia Nacional de la Historia, 1981.

Arata, Pedro et al. Investigación Vinícola, Informe de la Comisión de Investigación Vinícola designada por el Gobierno Nacional. Anales del Ministerio de Agricultura de la Nación,Tomo I. Buenos Aires, 1903.

Bialet Massé, Juan. Informe sobre el Estado de la Clase Obrera en la República Argentina. Buenos Aires: Hyspamérica, Tomo II, 1985 (Primera edición, 1904). 
Blanco, Eusebio. Manual del Viñatero en Mendoza, extractado y anotado sobre el Texto de la 4ta.Edición francesa del "Tratado de Vinificación" de Mr.Henry Machard. Buenos Aires: Imprenta Americana, 1870.

Botana, Natalio. El Orden Conservador. Buenos Aires: Sudamericana, 1994.

Chiaramonte, José C.Mercaderes del Litoral. Economía y Sociedad en la Provincia de Corrientes, primera mitad del siglo XIX. Buenos Aires; Fondo de Cultura Económica, 1991.

Cipolla, Cario M. (editor). Historia Económica de Europa. La Revolución industrial. Barcelona: Crítica, 1983.

Civit, Emilio. Los viñedos de Francia y los de Mendoza. Importante carta del Dr.Emilio Civit al Sr.Tiburcio Benegas. Mendoza: Tipografia Los Andes, 1887.

Clarín, diario. Buenos Aires, varios números, años 1997-1999.

Del Valle, María del Carmen y Solleiro,José Luis (coords.). El Cambio Tecnológico en la Agricultura y las Agroindustrias en México. México: Siglo XXI, 1996.

Do Amaral Filho, Jair y Pereira de Melo, María Cristina. Globalización o metamorfosis del Capitalismo. CICLOS en la Historia, la Economía y la Sociedad 14-15, 1998:5174.

El Constitucional, diario. Mendoza, años $1870 / 1881$.

El Ferrocarril, diario. Mendoza, años 1882/1889.

Ferrer,Aldo. Historia de la Globalización. Orígenes del Orden Económico Mundial. Buenos Aires: Fondo de Cultura Económica, 1994.

Furlani de Civit, María, Gutiérrez de Manchón, María, Pérez Romagnoli., Eduardo, Richard-Jorba, Rodolfo y Zamorano, Mariano. Transformaciones recientes en el oasis norte de Mendoza, Argentina. América Latina: Regiones en Transición. Madrid: Univ. de Castilla-La Mancha, 1991.

Furlani de Civit, María, García de Martín, Griselda, Gutiérrez de Manchón, Pedone, Claudia y Pérez Romagnoli, Eduardo. Modelo de transformación agroindustrial en Mendoza,Argentina.Mendoza:una Geografía en Transformación. Mendoza:Facultad de Filosofia y Letras-Universidad Nacional de Cuyo, 1996:127-160.

Furtado,Celso. La Economía Latinoamericana de la Conquista Ibérica a la Revolución Cubana. Santiago: Editorial Universitaria, 1969.

Galanti, Arminio N. La Industria Viti-Vinicola Argentina. Buenos Aires: Centro Viti-Vinícola de Mendoza, Tomo 1, 1900.

Garavaglia, Juan C. Economía, Sociedad y Regiones. Buenos Aires: Ediciones de la Flor, 1987.

Gobierno de Mendoza. Registro Oficial,años 1870/1902.

.Anuario Estadístico de la Provincia de Mendoza correspondiente al año 1887. Mendoza, 1889.

- Censo Provincial 1909. Buenos Aires: Cía. Sudamericana de Billetes de Banco, 1910.

Gutiérrez de Manchón, María J. Retroceso y Reconversión de Cultivos en los Oasis de Mendoza. Mendoza: una geografía en transformación. Mendoza: Facultad de Filosofía y Letras-Universidad Nacional de Cuyo, 1996:51-62.

Harvey, David. La Condición de la Posmodernidad. Investigación sobre los Orígenes del Cambio Cultural. Buenos Aires: Amorrortu editores, 1998.

Instituto Nacional de Vitivinicultura-INV Estadística Vitivinícola-INV 68. Mendoza: INV, 1969 a.

- Resultados del III Censo Vitícola Nacional - Año 1968. Mendoza: INV, 1969-b. Estadística Vitivinícola Argentina-1985. Mendoza: INV, 1987-a. 
Los Productos Vitivinícolas Argentinos en los Mercados Mutidiales-Año 1986, Mendoza: INV, 1987-b.

Kexel, G. La Electricidad y sus Aplicaciones en la Vitivinicultura. El Diario. Mendoza, 7 al 12 de julio de 1897.

Larrea Maldonado, Carlos. El Banano en el Ecuador. Transnacionales, Modernización y Subdesarrollo. Quito: Corporación Editora Nacional, 1987.

Lilley, Samuel. El progreso tecnológico y la Revolución Industrial. Historia Económica de Europa. La Revolución Industrial. Barcelona: Crítica. 1983:195-264.

Lemos, Abraham. Mendoza. Memoria descriptiva de la Provincia. Mendoza:Tipografía Los Andes, 1888.

Letourneau, Jocelyn. Canadá y el Tratado de Libre Comercio de América del Norte: desafíos y problemas. CICLOS en la Historia, la Economía y la Sociedad, 4, 1993:332.

Llaver, Mauricio. Inversiones en la Industria Vitivinícola. Temas del Mercosur 2,1997:5762.

Los Andes, diario, Mendoza, años 1882/1900 y suplemento Los Andes Económico, varios números, $1998-1999$.

Minsburg, Naum y Valle, Héctor W. (editores). El Impacto de la Globalización. La Encrucijada Económica del Siglo XXI. Buenos Aires: Ediciones Letra Buena, 1994.

Pavlovsky, Aarón. Informe presentado al Exmo. Sr.Ministro del Interior Dr.D. Bernardo de frigoyen, sobre los Trabajos ejecutados en la Escuela Nacional de Agricultura de Mendoza en el año 1884. Mendoza; Imprenta de La Palabra, 1884.

.Informe sobre vitivinicultura. La Provincia de Mendoza en su Exposición Interprovincial de 1885. Mendoza:Tipografia Bazar Madrileño, 1885.

Pérez Romagnoli, Eduardo y Richard-Jorba, Rodolfo. Una Aproximación a la Geografía del Vino en Mendoza: distribución y difusión de las bodegas en los comienzos de la etapa industrial. 1880-1910. Revista de Estudios Regionales 11. 1994:151-176.

Pérez Romagnoli, Eduardo. La Industria Metalúrgica Mendocina Fabricante de Máquinas y Equipos para la Transformación de Materia Prima de Base Agraria. Constitución y Caracterización de las Etapas. Boletín de Estudios Geográficos 89, Anexo, Tomo IV. 1995:897-906.

. Contribuciones para una Geografía Histórica de Mendoza: Industrias Inducidas por la Fabricación de Vino entre 1880 y 1930. Revista de Estudios Regionales 15/ 16.1996:53-88.

- Mendoza, núcleo de la metalurgia argentina fabricante de máquinas y equipos para la industria transformadora de materias primas de base agraria. Boletín de Estudios Geográficos 92. 1997:73-146.

Rapoport, Mario. La Globalización Económica: Ideologías, Realidad, Historia. CICLOS en la Historia, la Economía y la Sociedad 12. 1997:3-42.

República Argentina. Primer Censo de la República Argentina, verificado en los días 15, 16 y 17 de setiembre de 1869. Buenos Aires: Imprenta del Porvenir, 1872.

- Segundo Censo Nacional 1895. Buenos Aires, Tres tomos.

Richard-Jorba, Rodolfo y Pérez Romagnoli, Eduardo. La Década de 1870 en Mendoza: etapa de reorientación de la economía y el espacio hacia el dominio vitivinícola. Boletín de Estudios Geográficos 88. 1992:27-53.

- El Proceso de Modernización de la Bodega Mendocina.1860-1915. CICLOS en la Historia, la Economía y la Sociedad 7. 1994:119-155.

Richard-Jorba, Rodolfo. Conformación Espacial de la Viticultura en la Provincia de 
Mendoza y Estructura de las Explotaciones.1881-1900. Revista de Estudios Regionales 10. 1992:131-172.

Richard-Jorba, Rodolfo. Modelo Vitivinícola en Mendoza. Las Acciones de la Élite y los Cambios Espaciales Resultantes. 1875-1895. Boletín de Estudios Geográficos 89. 1994-a-:227-264.

. Inserción de la Élite en el Modelo Socioeconómico Vitivinícola de Mendoza.

1881-1900. Revista de Estudios Regionales 12. 1994 -b-:131-172.

- Hacía el Desarrollo Capitalista en la Provincia de Mendoza. Evolución de los

Sistemas de Explotación del Viñedo entre 1870 y 1900. Anales de la Sociedad Científica

Argentina 2 - Vol. 224.1994 -c-:1-34.

Poder, Economía y Espacio en Mendoza, 1850-1900. Mendoza. Facultad de Filosofía y Letras-Universidad Nacional de Cuyo, 1998.

Rodríguez, Mario Domingo. Influencia de la Estructura de los Viñedos de Mendoza y San Juan en la Exportación de Vinos y Uvas a los Estados Unidos. IDIA 252. 1968:1-21.

Sábato, Hilda. Capitalismo y Ganaderia en Buenos Aires. La fiebre del lanar, 1850-1890. Buenos Aires: Sudamericana, 1989.

Santos, Milton. De la Totalidad al Lugar. Barcelona: Oikos-Tau, 1996.

Schumpeter, Joseph. Capitalismo, Socialismo y Democracia. Barcelona: Editorial. Folio, 2 tomos (primera edición, 1942), 1996,

Sivera, Marcelo. Artículos periodísticos sobre vitivinicultura. Diario Los Andes (Los Andes Económico). Mendoza: varios números, 1998-1999.

Sklair, Leslie. Las Maquilas en México: una perspectiva global. Revista Mexicana de Sociología 2. 1992:163-183.

Vidal Villa, José María. Mundialización. Diez tesis y otros artículos. Barcelona: Icaria, 1996. Vinífera, número extraordinario 1997, Mendoza.

Zamorano, Mariano. ElViñedo en Mendoza. Boletín de Estudios Geográficos 23. 1959: 49-99. 